\title{
Trabajar sobre las conductas de riesgo previene enfermedades de transmisión sexual en mujeres
}

A randomized, controlled trial of a behavioral intervention to prevent sexually transmitted disease among minority women. Shain R, Piper J, Newton E et al. N Engl J Med 1999; 340: 93-100.

\section{Objetivo}

Diseñar y evaluar intervenciones específicas en las conductas sexuales que sirvan para disminuir las tasas de enfermedades de transmisión sexual (ETS) en mujeres Afro-Americanas e hispanas que viven en EE.UU.

\section{Diseño}

Ensayo clínico randomizado y controlado, con un seguimiento a 6 y 12 meses.

\section{Lugar}

Clínicas de Salud Pública de San Antonio, EE.UU.

\section{Pacientes}

Mujeres ( $n=947$ ) que hayan tenido una ETS no viral (Chlamydia, gonorrea, sífilis, o tricomonas ), y que hablaran inglés. A las pacientes se le ofreció un incentivo económico en cada visita para estimular su participación.

\section{Intervención}

Luego de dar su consentimiento informado se les realizó un examen general, rastreo para las ETS no virales, se las trató si era necesario, se les brindó el consejo habitual y se las recitó a los 6 y 12 meses para realizar un nuevo control. Luego de finalizada la visita inicial eran aleatorizadas en 2 grupos. El grupo control recibió el consejo habitual. El grupo intervención participó (en grupos de 5-6 mujeres en promedio, rango 3 -12) en encuentros semanales durante tres semanas consecutivas y con una duración de 3-4 hs cada uno. Este esquema de trabajo se basó en una adaptación que realizaron al AIDS Risk Reduction Model para guiar la recolección cualitativa de los datos a tener en cuenta para la planificación de los encuentros. En estos encuentros se trabajaba con las mujeres para: 1) Reconocer las conductas de riesgo (ej. discutir la selección de la pareja y demostrar que no hay manera de juzgar quien es "seguro"), 2) Comprometerse con su modificación (ej. enseñar como preguntarle a la pareja acerca de sus conductas habituales y de sus antecedentes), 3) Conocer el modo de uso del preservativo practicando con modelos plásticos, y 4) Adquirir las destrezas necesarias para esto (ej. enseñar destrezas básicas en relación a la disfunción sexual resultante del uso del preservativo y conocer formas de uso eróticas del mismo).

\section{Medición de resultados principales}

El resultado principal se definió como subsecuentes infecciones por Chlamydia o gonococo, detectadas por cultivos, en las visitas de los 6 y 12 meses.

\section{Resultados principales}

El análisis se realizó por intención de tratar. La mayoría de las mujeres que se infectaron en este período tuvieron sólo 1 episodio de infección. Las mujeres del grupo control tuvieron más episodios de infección que las del grupo intervención tanto para infecciones múltiples como únicas. (ver tabla)

El análisis multivariable* de los efectos de la intervención en infecciones subsecuentes mostró que las mujeres del grupo intervención tenían significativamente menos probabilidad que las mujeres del grupo control de tener una infección por chlamydia o gonococo a los 6 meses, entre los 6-12 meses o a los 12 meses. El efecto de la intervención no disminuyó con el tiempo.

Infecciones por Clamydia y Gonococo en el período de seguimiento

\begin{tabular}{l|l|l|l|l|c}
\hline $\begin{array}{l}\text { Período } \\
\text { Estudiado }\end{array}$ & $\begin{array}{l}N^{\circ} \text { total de } \\
\text { Participantes }\end{array}$ & \multicolumn{2}{|c|}{$\begin{array}{c}N^{\circ} \text { Participantes Infectados } \\
\text { G. intervención } \\
N^{*} \text { (\% del grupo) }\end{array}$} & $\begin{array}{c}\text { Odds Ratio } \\
\text { G. control } \\
\text { (IC9 5\% })\end{array}$ & $p$ \\
\hline 0 a 6 meses & 509 & $30(11,3)$ & $42(17,2)$ & $0,58(0,34-0,89)$ & 0,05 \\
\hline 6 a 12 meses & 545 & $26(9,1)$ & $46(17,7)$ & $0,49(0,29-0,83)$ & 0,008 \\
\hline 0 a 12 meses & 549 & $48(16,8)$ & $71(26,9)$ & $0,52(0,34-0,81)$ & 0,004 \\
\hline
\end{tabular}

\section{Conclusiones}

La intervención conductual tendiente a reducir el riesgo en mujeres hispanas y Afro-Americanas (pertenecientes a minorías en EE.UU.) con alto riesgo de contraer ETS ha demostrado ser efectiva.

\section{COMENTARIO}

Este estudio nos habla acerca de una intervención efectiva para reducir el riesgo de contraer determinadas ETS en mujeres afro-americanas e hispanas (mexico-americanas) que viven en EE.UU., ambas consideradas como minorías en ese país. Si uno piensa en la posibilidad de realizar una intervención similar en su lugar de trabajo se justificaría por varias razones. Desde el punto de vista epidemiológico, se sabe que las ETS, incluyendo el SIDA, significan anualmente un alto costo tanto económico como médico en cuanto a las complicaciones y secuelas. Se conoce que las mujeres tienen mayor riesgo que los hombres de contraer una ETS, y que en los últimos años las tasas de ETS en jóvenes sobre todo en aquellos pertenecientes a grupos minoritarios han aumentado; siendo por ej. el contagio del SIDA en la adolescencia la principal causa de SIDA en los adultos. ${ }^{1} 0$ tro factor de riesgo asociado a las ETS son las condiciones socioculturales, sabiendo que los grupos marginales (sea por raza, conducta sexual o pobreza) son los más afectados.
Pensando en estos datos podríamos rápidamente intentar trasladar esta experiencia a nuestra práctica, pero hay que tener en cuenta varios puntos. Este trabajo fue realizado sobre un grupo con características particulares (ej. minorías, inmigrantes) no trasladables automáticamente a cualquier otro grupo. Uno de los motivos del éxito de esta intervención y que tendría que cumplir cualquier otra experiencia similar para ser exitosa, estaría dada por la realización de un relevamiento previo (en este trabajo utilizaron la metodología de los "grupos de fo$\mathrm{CO}^{*} "$ ) acerca de las costumbres, creencias, mitos, necesidades de la población en estudio, para conocer con "quien" estaremos trabajando. Otro punto a tener en cuenta para pensar en la aplicabilidad de esta experiencia en forma masiva es la influencia que podemos presuponer que tuvo el incentivo económico que recibieron las pacientes para su continuidad en el tratamiento, lo cual influiría en la realización del trabajo y podría sobreestimar la efectividad de la intervención.

Dra. Daniela Epstein Unidad de Medicina Familiar y Preventiva. Hospital Italiano de Buenos Aires. 